\title{
One-step Low Temperature Reactive Consolidation of High Purity Nanocrystalline $\mathrm{Mg}_{2} \mathrm{Si}$
}

\author{
Shaoping Chen ${ }^{a, b^{*}}$, Xia Zhang ${ }^{a}$, Wenhao Fan ${ }^{a^{*}}$, Tanghong Yi ${ }^{\mathrm{c}}$, Dat V. Quach ${ }^{\mathrm{d}}$, \\ Sabah Bux ${ }^{\mathrm{e}}$, Qingsen Meng ${ }^{a, b}$, Susan M. Kauzlarich ${ }^{\mathrm{c}}$, Zuhair A. Munir ${ }^{\mathrm{d}}$
}

${ }^{a}$ Key Laboratory of Interface Science and Engineering in Advanced Materials, Ministry of Education, Taiyuan University of Technology, Taiyuan 030024, China.

${ }^{b}$ College of Materials Science and Engineering, Taiyuan University of Technology, Taiyuan, 030024, China.

${ }^{c}$ Department of Chemistry, University of California, Davis, CA 95616, USA.

${ }^{d}$ Department of Chemical Engineering and Materials Science, University of California, Davis, CA 95616, USA.

${ }^{e}$ Jet Propulsion Laboratory, California Institute of Technology, 4800 Oak Grove Drive, Pasadena, CA 91109

*Author for correspondence. Shaoping Chen, Tel: 86-351-601007.

Email: chenshaoping@tyut.edu.cn (S.P.Chen),

Postal address: 79 west Yingze Street, College of Materials Science and Engineering, Taiyuan, Shanxi, China, 030024,

Wenhao Fan, Email: fanwenhao1979@163.com (F.W.Hao). 


\section{Abstract}

Bulk Nanocrystalline $\mathrm{Mg}_{2} \mathrm{Si}$ thermoelectric materials were synthesized and consolidated in a one-step process through a solid-state reaction between magnesium hydride and silicon, using the spark plasma sintering (SPS) method. The hydrogen produced in the process alleviates the problem of the oxidation of $\mathrm{Mg}$. The samples were reactively sintered at temperatures in the range $723-823 \mathrm{~K}$ and under a uniaxial pressure in the range of 71-164 $\mathrm{MPa}$ in $5 \mathrm{~min}$. Powder X-ray diffraction (XRD) analysis showed the products to be pure $\mathrm{Mg}_{2} \mathrm{Si}$. The grain size of the consolidated samples was less than $500 \mathrm{~nm}$, as determined by transmission electron spectroscopy (TEM). Residual nano-pores were observed by scanning electron microscopy at grain boundaries; their presence is believed to be the consequence of hydrogen evolution during the reactive sintering. The effect of synthesis temperature and pressure on crystallite size, density, and transport properties was determined. The results showed that use of $\mathrm{MgH}_{2}$ instead of $\mathrm{Mg}$ in the one-step method prevents the formation of $\mathrm{MgO}$. The addition of 1 at. $\% \mathrm{Bi}$ as a dopant improved the power factor significantly. Samples with 1 at.\% Bi had a $Z T$ of 0.6 at $775 \mathrm{~K}$.

Key words: $\mathrm{Mg}_{2} \mathrm{Si}$; Reactive Sintering; $\mathrm{MgH}_{2}$; SPS; Nanocrystalline. 


\section{Introduction}

Thermoelectric (TE) materials have been widely investigated in recent years for the conversion of waste heat into electrical energy and thus increasing the energy efficiency in various applications, for example in automobiles [1]. They can also be used in independent energy generators, for mobile applications such as space vehicles [2]. Of the many classes of materials investigated for this purpose, silicides (e.g., $\mathrm{Mg}_{2} \mathrm{Si}, \mathrm{MnSi}_{\mathrm{x}}, \beta-\mathrm{FeSi}_{2}$, and $\mathrm{Ru}_{2} \mathrm{Si}_{3}$ ) [3-8] have received considerable attention. And of these, magnesium silicide, $\mathrm{Mg}_{2} \mathrm{Si}$, has been the focus of widespread investigations [9]. It is attractive as a TE material because of its intrinsic properties, as well as the abundance and nontoxicity of its constituent elements.

$\mathrm{Mg}_{2} \mathrm{Si}$ has an antifluorite structure with the $\mathrm{Si}$ atoms in face-centered cubic positions and the $\mathrm{Mg}$ atoms in tetrahedral sites. It is a narrow gap semiconductor with an indirect bandgap, $E_{\mathrm{g}}$, of $0.77 \mathrm{eV}$ [10]. In addition to its use as a TE material for temperatures in the range $500-800 \mathrm{~K}, \mathrm{Mg}_{2} \mathrm{Si}$ has also been used in other applications, for example, in lithium-ion batteries [11,12] and solar cell devices [13]. $\mathrm{Mg}_{2} \mathrm{Si}$ has a low density, high melting point, and good mechanical properties [14]. This material is reported to be oxidation resistance up to $723 \mathrm{~K}$, [15] which may be taken as a safe upper limit of its application.

Doping magnesium silicide with both $\mathrm{n}$ - and p-type impurities to improve the dimensionless figure of merit, $Z T$, has been investigated [16]. The figure of merit is defined as $Z T=\left(S^{2} \sigma T\right) / \kappa$, where $S$ is the Seebeck coefficient, $\sigma$ is the electrical 
conductivity, $\kappa$ is the thermal conductivity (being the sum of lattice (phonon), $\kappa_{\mathrm{L}}$, and electronic, $\kappa_{\mathrm{e}}$, contributions), and $T$ is the absolute temperature. Undoped $\mathrm{Mg}_{2} \mathrm{Si}$ has a small $Z T$ value of about 0.1 . However, small additions of dopants have been shown to increase $Z T$ significantly. For example, doping $\mathrm{Mg}_{2} \mathrm{Si}$ with $\mathrm{Sn}$ has resulted in a $Z T$ of over 1.1 at a temperature of about $800 \mathrm{~K}[3,4]$. This $Z T$ value is comparable to those obtained from conventional TE materials including $\mathrm{Pb}$ telluride, $\mathrm{Si}$-Ge alloys, and $\mathrm{CoSb}_{3}$ in the intermediate temperature range $(400-800 \mathrm{~K})$. However, as indicated above, $\mathrm{Mg}_{2} \mathrm{Si}$ has the advantages of low cost, abundance and nontoxicity of its elements compared with the conventional TE materials.

$\mathrm{Mg}_{2} \mathrm{Si}$ has been synthesized by several methods, including melting and solidification [3,17], mechanochemical synthesis [18], vertical Bridgman method [19], microwave heating [20], combustion synthesis [21], and solid-state reaction [22]. As indicated above, doped $\mathrm{Mg}_{2} \mathrm{Si}$ has been shown to exhibit attractive figure of merit. For example, Tang et al. [23] used a two-step reaction followed by the spark plasma sintering (SPS) method to prepare Bi-doped $\mathrm{Mg}_{2.16} \mathrm{Si}_{0.4} \mathrm{Sn}_{0.6}$ solid solutions. When the content of $\mathrm{Bi}$ is 3 at.\%, the solid solution had a $Z T$ value of 1.4 at $800 \mathrm{~K}$. Zhang et al. [24] used melt spinning followed by SPS to prepare Bi-doped $\mathrm{Mg}_{2}\left(\mathrm{Si}_{0.4} \mathrm{Sn}_{0.6}\right)$ and obtained a $Z T$ value of 1.2 at $750 \mathrm{~K}$ when the content of Bi was 3 at.\%.

Compared to $\mathrm{Mg}_{2} \mathrm{Si}_{\mathrm{x}} \mathrm{Sn}_{1-\mathrm{x}}, \mathrm{Mg}_{2} \mathrm{Si}$ is a simpler and relatively more stable system when exposed to air at high temperature. This aspect provides an advantage, although its figure of merit is not as high as that of $\mathrm{Mg}_{2} \mathrm{Si}_{\mathrm{x}} \mathrm{Sn}_{1-\mathrm{x}}$. As indicated above, $\mathrm{Mg}_{2} \mathrm{Si}$ has been prepared by melting and solidification. However, due to the volatility and 
oxidation tendency of $\mathrm{Mg}$, and the significant difference between the melting point of $\mathrm{Mg}(923 \mathrm{~K})$ and that of $\mathrm{Si}(1687 \mathrm{~K})$, preparing a stoichiometric compound by this method is difficult [25]. To suppress the loss of $\mathrm{Mg}$, Gao et al. [26] used a $\mathrm{B}_{2} \mathrm{O}_{3}$ flux method to produce $\mathrm{Mg}_{2}(\mathrm{Si}, \mathrm{Sn})$ solid solutions. In contrast, Yi et al. [27] used a modified solid-state process by reacting $\mathrm{MgH}_{2}$ and $\mathrm{Si}$ at a low temperature of $623 \mathrm{~K}$ to prepare $\mathrm{Mg}_{2} \mathrm{Si}$, thus ameliorating the problem of $\mathrm{Mg}$ loss. A $Z T$ value of 0.7 was obtained at $775 \mathrm{~K}$ for Bi-doped $\mathrm{Mg}_{2} \mathrm{Si}$.

In this paper, 1 at.\% $\mathrm{Bi}$-doped $\mathrm{Mg}_{2} \mathrm{Si}$ was prepared by a one-step synthesis process, in which both the reaction between $\mathrm{MgH}_{2}$ and $\mathrm{Si}$ and the consolidation is accomplished by the SPS method. The synthesis reaction is

$$
2 \mathrm{MgH}_{2}+\mathrm{Si}=\mathrm{Mg}_{2} \mathrm{Si}+2 \mathrm{H}_{2}(\mathrm{~g})
$$

which reaches completion in several minutes. $\mathrm{MgH}_{2}$ decomposes at $623 \mathrm{~K}$, and the hydrogen produced alleviates the problem of the oxidation of $\mathrm{Mg}$. We report on the effect of sintering temperature and pressure on the grain size, density, and transport properties of $\mathrm{Mg}_{2} \mathrm{Si}$. 


\section{Experimental Materials and Methods}

The experiments were carried out in a Sumitomo, Dr. Sinter, Model 1050 SPS apparatus. The graphite assembly included a small set (12.75 mm inner diameter and $19.8 \mathrm{~mm}$ outer diameter) and a bigger set (20 mm inner diameter), which were both made of graphite. The starting materials used in this research were powders of magnesium hydride (Alfa Aesar, powder, -325 mesh, 98\% pure) and silicon (Aldrich, powder, -325 mesh, 99\% pure). Bi (Johnson Matthey Electronics, rod, 99.9999\% pure) was used as an n-type dopant. In order to ensure homogeneous distribution, 1 at.\% Bi was mixed with the stoichiometric Si and ball-milled in a mixer/mill (SPEX, $8000 \mathrm{M})$ for $12 \mathrm{~h}$ with $15 \mathrm{~min}$ intervals of on and off to obtain nanopowder (16-21 $\mathrm{nm})$, as determined by powder X-ray methods. Then magnesium hydride was added and mixed for another $30 \mathrm{~min}$ with a ball-to-powder mass ratio of 7.2:1. The mixture about $200 \mathrm{mg}$ was loaded into a graphite die and then reacted and consolidated by the SPS method. The prediction from theoretical calculations suggested that Bi could overcome a lower energy barrier to substitute for $\mathrm{Si}$ rather than $\mathrm{Mg}^{[15]}$. The experimental observations indicated that $\mathrm{Bi}$ was a substitutional dopant for $\mathrm{Mg}$ at the grain boundaries and for $\mathrm{Si}$ within grains [26]. In this work the molar ratio of $\mathrm{MgH}_{2}: \mathrm{Si}: \mathrm{Bi}$ was set as 2.0:0.99:0.01.

A schematic diagram of the heating sequence of the sample in the SPS is shown in Fig. 1. The powder was heated to $623 \mathrm{~K}$ in $10 \mathrm{~min}$ and then allowed to remain at this temperature for $10 \mathrm{~min}$ to ensure completion of the reaction. Then the 
temperature was increased to a selected value in $2 \mathrm{~min}$ and held for $5 \mathrm{~min}$. As the schematic shows, the applied uniaxial pressure was increased during the second temperature ramp and held constant afterwards. The value of the applied pressure was relatively low (about $18 \mathrm{MPa}$ ) in the reaction stage $(623 \mathrm{~K})$ to allow for the expulsion of the produced hydrogen gas (Eq. (1)). The subsequent increase in pressure (71-164 $\mathrm{MPa}$ ) was made to achieve effective consolidation. All experiments were carried out in the SPS under a vacuum of $6 \mathrm{~Pa}$.

The temperature of the samples was measured by a W-5\%Re-W-26\%Re thermocouple (OMEGA, diameter $0.3 \mathrm{~mm}$ ), which was placed in a hole drilled in the graphite die; the tip of the thermocouple was about $2 \mathrm{~mm}$ from the sample. The microstructure and phase composition of the prepared samples were determined by scanning electron microscopy (SEM, FEI XL30-SFEG), energy dispersive spectroscopy (EDS, HKL), transmission electron spectroscopy (TEM, HT-800), and X-ray diffraction analysis (XRD, KEVEX SIGMA, TD-3000 XRD, Cu target). Transport properties of the samples were measured on pellets polished from the SPS sintered samples to a thickness of $1 \mathrm{~mm}$.

The Seebeck coefficient and electrical conductivity were measured by a Seebeck coefficient/electric resistance measuring system (ZEM-1, ULVAC Inc., Japan). A temperature difference of $4{ }^{\circ} \mathrm{C}$ between the cool and hot ends of the sample was used for the Seebeck coefficient measurement. The Hall coefficient was measured in a high temperature apparatus with a constant magnetic field about 9000 Gauss at the Jet Propulsion Laboratory (Pasadena, CA). The carrier density $(n)$ was calculated from 
the Hall coefficient $\left(R_{\mathrm{H}}\right)$ based on $n=1 / R_{\mathrm{H}} e$, and the Hall mobility $\left(\mu_{\mathrm{H}}\right)$ was calculated from the Hall coefficient $\left(R_{\mathrm{H}}\right)$ and the resistivity values according to equation $\mu_{\mathrm{H}}=R_{\mathrm{H}} / \rho$. The thermal conductivity was calculated by $\kappa=\alpha \cdot C_{\mathrm{p}} \cdot \rho$, where $\alpha$ is the thermal diffusivity, $\rho$ is the sample density, and $C_{\mathrm{p}}$ is the specific heat capacity. The parameters $\alpha$ and $C_{\mathrm{p}}$ were measured on NETSCH LFA457/ DSC404, and $\rho$ was measured by the Archimedes method. The figure of merit $Z T$ was then calculated based on the equation $Z T=\left(S^{2} \sigma T\right) / \kappa$. More detail about thermoelectric properties measurements and calculation can be found in our previous work [27]. 


\section{Results and Discussion}

\subsection{Analysis and microstructure of reactively sintered samples}

The XRD patterns of samples sintered at various temperatures and pressures are shown in Fig. 2. Samples were sintered at $723 \mathrm{~K}$ under three different pressures (100, 137 , and $164 \mathrm{MPa}$ ) and at $773 \mathrm{~K}$ and $823 \mathrm{~K}$ under a pressure of $71 \mathrm{MPa}$. For all samples, the XRD peaks indicate the presence of the antifluorite structure $(F m \overline{3} m)$ of $\mathrm{Mg}_{2} \mathrm{Si}$. No evidence is seen for the presence of $\mathrm{MgO}$ in the samples sintered at $723 \mathrm{~K}$; its principal peak is indicated by an arrow at $2 \theta$ of about $43^{\circ}$. However, when the sintering temperature was increased to $773 \mathrm{~K}$ and higher, evidence for the presence of $\mathrm{MgO}$ is indicated by a very small peak, as the figure shows. The formation of $\mathrm{MgO}$ may be considered by the following reaction:

$$
3 \mathrm{MgH}_{2}+\mathrm{Si}+2 \mathrm{O}_{2}(\mathrm{~g})=\mathrm{MgO}+\mathrm{Mg}_{2} \mathrm{Si}+3 \mathrm{H}_{2} \mathrm{O}(\mathrm{g})
$$

which has a $\Delta \mathrm{G}$ of $-1281.8 \mathrm{~kJ}$ at $773 \mathrm{~K}$. This value is considerably higher (more negative) than that of $\mathrm{Eq}(1)$ at the same temperature, $-122.7 \mathrm{~kJ}$. Since $\mathrm{MgO}$ was not observed at temperatures lower than $773 \mathrm{~K}$, despite the higher driving force for its formation (Eq.2), it may be speculated that the process is kinetically controlled, becoming more likely at higher temperatures.

Thermodynamic calculations show that Eq.(1) has a negative Gibbs free energy at a low temperature $(<288 \mathrm{~K})$ and thus the reaction can proceed at lower temperatures, which has been shown in a previous research [27]. In this work, when the mixture was 
held at $623 \mathrm{~K}$ for $10 \mathrm{~min}$, the magnesium hydride decomposed nearly completely with the evolution of hydrogen, as evidenced by the change in the vacuum level in the SPS chamber. At about $563 \mathrm{~K}$, the magnesium hydride began to decompose, producing hydrogen during the heating period, the vacuum level reached 29-31 $\mathrm{Pa}$ at about 623 $\mathrm{K}$ and then decreased to the $6 \mathrm{~Pa}$ level in several seconds. Comparing the (220) peaks from samples prepared under different temperature and pressure conditions, it becomes apparent that both parameters play a role in the reaction process. An increase in both resulted in an increase in the height of the peak, as shown in the figure. In this regard, the effect of temperature is more pronounced than that of pressure.

The microstructure of the reactively sintered sample is shown in the SEM image of Fig. 3(a). The reactive process resulted in the formation of a very dense structure with fine lamellae. A few nano-pores (yellow arrows) residing in the grains and at grain boundaries can be observed. These, we believe, are remnants of the pores created by the hydrogen produced during the decomposition of the hydride. Indirect evidence for this comes from the observations of delayed appearance of fracture patterns on the surface of some samples, as shown in Fig. 3(b). Infrequently, a sintered sample which appeared to be perfect after the process developed fracture patterns or pores after one or two days. Our hypothesis for this phenomenon is that during the decomposition of the hydride, atomic hydrogen diffuses easily through the lattice of $\mathrm{Mg}_{2} \mathrm{Si}$ and escapes as a gas to the surroundings. But it may also diffuse to grain boundaries and become trapped, and in time its increased pressure can cause the observed delayed fracture. The SEM fracture image in Fig. 3(a) shows the presence of 
hydrogen pores in grains and at grain boundaries. It has been found in our experimental work that the mixture can be consolidated even at $623 \mathrm{~K}$ by holding for 10-15 min; however the samples had very low density. At this temperature, the kinetics of mass transfer is relatively low for the escape of the hydrogen.

The presence of nano-pores is expected to lower the thermal conductivity through the scattering of phonons and electrons, and also to provide a retardation effect to grain growth [28]. Fig. 3(c) shows a selected-area-diffraction (SAD) pattern of the product with dense and fine crystallites. The TEM image of the synthesized $\mathrm{Mg}_{2} \mathrm{Si}$ shows a grain size of less than $500 \mathrm{~nm}$ with nano-pores of less than $50 \mathrm{~nm}$ in size (shown by the yellow arrows).

A homogeneous distribution of the dopant $\mathrm{Bi}$ is important for improvements to the figure of merit of thermoelectric materials. Results of the backscattered electron (BSE) images and elemental maps of the SPS pellets (for sample sintered at $823 \mathrm{~K}$ and $71 \mathrm{MPa}$ ) are shown in Fig. 3(d). The bright areas in the BSE image are Si-rich with minor amounts of $\mathrm{Ti}$ and Fe according to the EDS qualitative calculation. These are probably purities in the starting materials. The Bi elemental map shows a well distributed element in the matrix with an apparent preference at grain boundary sites, as indicated in the inset. This observation is in agreement with results of previous work by others [26] and with previous observation in our reported work [27].

\subsection{Effect of pressure and temperature on density and crystallite size}

To further understand the effect of pressure and temperature on the crystallite size and density of the samples, additional experiments were carried out. The 
crystallite size of different samples was calculated by X-ray line-broadening analysis using the Scherrer equation by fitting all peaks. In this work, all X-ray diffraction was conducted on samples milled into powder. The density of pellet was determined by the Archimedes method using a solvent of toluene with a density of $0.865 \mathrm{~g} \cdot \mathrm{cm}^{-3}$. The dependence of density and crystallite size on pressure of the reactively sintered samples is shown in Fig. 4(a). It should be noted that the measured density by the Archimedes method is a little higher than the theoretical value, probably the result of contamination by the toluene due to repeated use, but the difference is within standard deviation.

The density used for thermal conductivity calculation is a geometric one. The crystallite size of samples reactively sintered at $723 \mathrm{~K}$ increases linearly with pressure, while their density increases asymptotically to a maximum. When the pressure was increased from 71 to $164 \mathrm{MPa}$, the crystallite size increases by $29.0 \%$ while the density remained nearly constant in this range, implying that at this temperature $(723 \mathrm{~K})$ a pressure threshold of about $71 \mathrm{MPa}$ is required in order to achieve the highest density. As predicted by classic sintering theory [29], grain boundary mobility increases with an increase in the applied pressure. With pore elimination, the rate of grain growth increases and the sample becomes denser. In contrast, high porosity retards grain growth by a pinning effect and the reduction of mass transfer. Thus samples sintered at lower pressures show poor density and small crystallite size. The dependence of density on sintering temperature of samples prepared under $71 \mathrm{MPa}$ is shown in Fig. 4(b); the density increased with an increase 
in temperature. The sample sintered at $823 \mathrm{~K}$ under a pressure of $71 \mathrm{MPa}$ had a density of $2.058 \mathrm{~g} \cdot \mathrm{cm}^{-3}$, while that sintered at $723 \mathrm{~K}$ under a pressure of $164 \mathrm{MPa}$ had a density of $2.041 \mathrm{~g} \cdot \mathrm{cm}^{-3}$. In both cases, the effect of pressure on density is relatively minor, while that of temperature is more significant.

\subsection{Thermoelectric property evaluations}

The trends of electrical resistivity, Seebeck coefficient, and power factor, $P_{\mathrm{F}}=$ $\sigma S^{2}$ ( $\sigma$ is the electrical conductivity and $S$ is the Seebeck coefficient), of samples prepared under different conditions (pressure and temperature) are shown in Fig. 5. The resistivity decreases with increasing temperature, an expected characteristics of semiconducting materials. The negative sign of the Seebeck coefficient confirms the samples as n-type. The results show that the contribution of the electrical conductivity to the power factor is dominant, despite the decrease in $S$. For samples sintered at 723 $\mathrm{K}$ the power factor shows a more rapid increase above $550 \mathrm{~K}$, an observation related to the contribution of intrinsic excitation to the electrical conductivity. The figure also shows that temperature plays a more important role than pressure in determining the electrical properties of samples prepared at $723 \mathrm{~K}$. The power factor of samples prepared at this temperature under a pressure of $164 \mathrm{MPa}$ has a $P_{\mathrm{F}}$ peak value of $1.37 \times 10^{-3} \mathrm{~W} / \mathrm{m} / \mathrm{K}^{2}$, while that prepared at $823 \mathrm{~K}$ under a pressure of $71 \mathrm{MPa}$ has a $P_{\mathrm{F}}$ peak value of $1.73 \times 10^{-3} \mathrm{~W} / \mathrm{m} / \mathrm{K}^{2}$.

Tani and Kido [30] investigated the thermoelectric properties of Bi-doped $\mathrm{Mg}_{2} \mathrm{Si}$ synthesized from the elements. They prepared samples with Bi concentration ranging 
from 0 to 2 at.\% and reported a solubility limit of $\mathrm{Bi}$ in $\mathrm{Mg}_{2} \mathrm{Si}$ at 1.3 at.\%. In contrast to this work, their results showed an increase of the electrical resistance with an increase in temperature. The onset of intrinsic contributions at higher temperatures leads to expectations of higher conductivity. In the cited work a maximum $Z T$ value of 0.86 at $862 \mathrm{~K}$ was reported for samples containing 2 at.\% $\mathrm{Bi}$ [30]. In view of the 1.3 at.\% solubility limit of $\mathrm{Bi}$, the higher $Z T$ value obtained is for samples presumably containing free $\mathrm{Bi}$, and thus the high $\mathrm{ZT}$ may be a consequence of the role of the $\mathrm{Bi}$ inclusions and not an intrinsic effect.

In order to determine the scattering mechanism, the Hall mobility of samples with higher $P_{\mathrm{F}}$ values (sintered under $71 \mathrm{MPa}$ at $773 \mathrm{~K}$ and $823 \mathrm{~K}$ ) was measured. The dependence of Hall mobility on temperature is shown in Fig. 6. Generally, the Hall mobility changes with temperature following a function of the form $\mu \sim T^{3 / 2}$ when ionized impurity scattering effect dominates. In contrast, scattering from acoustic phonons usually dominates at high temperatures, and has a dependence of $\mu$ $\sim T^{3 / 2}[31]$. The results in this work show that both curves of Fig. 6 approximate a $T^{3 / 2}$ dependence in the measured temperature range, indicating that ionized impurity scattering is the dominant mechanism. In this work reaction and consolidation are accomplished simultaneously at lower temperatures. The reaction is accompanied by the evolution of hydrogen, some of which was trapped in the product forming the observed nano-pores. The presence of nano-pores acted as termination of acoustic phonons transmission, and contributed subsequently to an effective decrease in acoustic phonons scattering of electrons even at high temperatures. As a result the effect of acoustic phonons scattering of electrons is not strong in the temperature range of this study. Bi atoms at grain boundaries can act as neutral impurity scattering centers, and they has a certain perturbation effect on the periodic potential field, especially at low temperature when both lattice vibration scattering and ionized 
impurity scattering are weak. Bux, et al. [18] and Yi, et al. [27] have reported the presence of the dopant $\mathrm{Bi}$ at grain boundaries in their samples which were synthesized by high-energy ball milling in one case [18] and long-time solid-state reaction in another case [27]. In this study, the simultaneous reaction and consolidation process was accomplished in less than half an hour at a relatively low temperature. Thus it is likely that more Bi would be at grain boundaries leading to the expectation of a not very strong scattering of electron even at high temperature. This would explain the lower Hall mobility and carrier concentration.

Fig. 7 shows the change in carrier concentration over the temperature range of 300-800 K for samples prepared at different conditions. The figure shows a significant effect of the sintering temperature on carrier concentration. A nearly factor of two increase in carrier concentration is observed as the sintering temperature was increased from 773 to $823 \mathrm{~K}$. An increase in sintering temperature facilitates the accommodation of the $\mathrm{Bi}$ atoms on lattice positions, leading to higher carrier concentration. The increase in carrier concentration for samples sintered at $773 \mathrm{~K}$ is continuous while that of samples sintered at $823 \mathrm{~K}$ remains rather constant over the entire temperature range, possibly indicating some contributions from other competing scattering mechanisms.

The temperature dependence of lattice thermal conductivity of samples prepared in this work is shown in Fig. 8. All samples have a total thermal conductivity lower than $2.2 \mathrm{~W} / \mathrm{m} / \mathrm{K}$ at temperatures higher than $700 \mathrm{~K}$. These values are significantly lower than those reported by others for doped $\mathrm{Mg}_{2} \mathrm{Si}$ materials prepared by traditional methods $[18,20,22]$. We attribute this to the purity of the product (lack of $\mathrm{MgO}$ ), to 
the presence of nano-pores, and also to the small grain size (hence higher concentration of grain boundaries).

The results also show that the thermal conductivity increases with an increase in the sintering temperature and pressure, possibly the consequence of higher density and lower concentration of nano-pores. The lattice thermal conductivity, $\kappa_{\mathrm{L}}$, has a similar trend with temperature to that of the total thermal conductivity because of the negligible electron contribution. The lattice thermal conductivity is calculated from $\kappa_{\mathrm{L}}$ $=\kappa_{\mathrm{T}}-\kappa_{\mathrm{E}}$, where $\kappa_{\mathrm{T}}$ is the total measured thermal conductivity, and $\kappa_{\mathrm{E}}$, is the electronic thermal conductivity. The latter is calculated from the Wiedemann-Franz law, $\kappa_{E}=$ $\mathrm{L}_{0} \sigma T$, where $\mathrm{L}_{0}$ is the Lorenz number, $\sigma$ is the electrical conductivity, and $T$ is the absolute temperature. The lattice thermal conductivity $\kappa_{\mathrm{L}}$ increased by $12.9 \%$ and $54.4 \%$, respectively, when the sintering temperature increased from $773 \mathrm{~K}$ to $823 \mathrm{~K}$ and the pressure increased from $100 \mathrm{MPa}$ to $164 \mathrm{MPa}$. The difference in the values of $\kappa_{\mathrm{L}}$ for all the samples becomes smaller as the temperature is increased. This can be taken as indicative of a crystal lattice vibration that is not significantly stronger at higher temperature than at $500 \mathrm{~K}$. It would likely be due to the contribution of nano-pores that act as termination regions of acoustic phonons transmission.

The dependence of the figure of merit, $Z T$, on temperature of all samples is shown in Fig. 9. The figure of merit increases with increasing temperature. For the sample sintered at $823 \mathrm{~K}$ under a pressure of $71 \mathrm{MPa}$, the figure of merit is 0.60 at $775 \mathrm{~K}$, with projected higher values at temperatures beyond this value. In comparison, previous investigations have reported a maximum $Z T$ value of 0.7 at $775 \mathrm{~K}$ and 0.86 
at $862 \mathrm{~K}$ for samples containing 1 at. $\%$ and 2 at.\% $\mathrm{Bi}$, respectively [27,30]. The advantage of this method is short duration, being completed in less than half an hour for the simultaneous reaction and consolidation.

\section{Conclusions}

Dense bulk nanocrystalline $\mathrm{Mg}_{2} \mathrm{Si}$ thermoelectric materials doped with 1 at.\% Bi were obtained by reacting $\mathrm{MgH}_{2}, \mathrm{Bi}$, and $\mathrm{Si}$ in a one-step synthesis and consolidation process, using the SPS method. The process minimizes the formation of the oxide $(\mathrm{MgO})$. It also produced a dense product with small grain size of less 500 $\mathrm{nm}$. The effects of temperature and pressure on crystallite size, density, and transport properties of the product were investigated. Microscopic observations showed the presence of nano-pores, which are believed to originate from the evolution of hydrogen in the synthesis process. The presence of the pores contributes to a decrease in the thermal conductivity and acts to retard grain growth during consolidation. Transport property measurements confirmed the low thermal conductivity of samples prepared by this method. A figure of merit, $Z T$ of $\sim 0.60$ is reached at $775 \mathrm{~K}$ for a sample sintered at $823 \mathrm{~K}$ under a pressure of $71 \mathrm{MPa}$. 


\section{Acknowledgments}

Part of this work was performed at the Jet Propulsion Laboratory, California Institute of Technology under contract with the National Aeronautics and Space Administration. This work was supported by the NASA Science Missions Directorate's Radioisotope Power Systems Technology Advancement Program. The authors thank Tela X. Favaloro for some preliminary transport properties measurements and Ali Shakouri for useful discussion. The funding support of NSFDMR1100313, NSF/DOE and Partnership CBET-1048799 is acknowledged. We also thank the financial support from National Science Fund for Young Scholars (Grant No 51101111), Research Project Shanxi Scholarship Council of China (Grant No 2012-031), and Program for the Top Young Academic Leaders of Higher Learning Institutions of Shanxi. 


\section{References}

[1]G. J. Snyder and E. S. Toberer, Nat. Mate., 2008, 7, 105-114.

[2]M. Zebarjadi, K. Esfarjani, M. S. Dresselhaus, Z. F. Ren and G. Chen, Energ.\& Environ. Sci., 2012, 5, 5147-5162.

[3]V. K. Zaitsev, M. I. Fedorov, E.A. Gurieva, I.S. Eremin, P.P. Konstantinov, A.Y. Samunin, and M.V. Vedernikov, Phys. Rev., B, 2006, 74, 045207.

[4]W.Liu,X.J Tan,K.Yin,H.J.Liu,X.F.Tang,J.Shi,Q.J.Zhang and Ctirad Uher. Phys.Rev.Lett.2012,108, 166601.

[5]Q. Hou, Z. Wang, and Y. He, Appl. Phys.A, 2005, 80(8), 1807-1811.

[6]Q. Hou, W. Zhao, Y. Chen, D. Liang, X. Feng, H. Zhang, and Y. He, Phys. Status Solidi A, 2007, 204, 3429-3437.

[7]H. Nagai, K. Nagai, T. Katsura, S. Katsuyama, K. Majima, and M. Ito, Mater. Trans.JIM, 1998, 39, $1140-1143$.

[8]B. Vining and C.E. Allevato, in Proceedings of the Intersociety Energy Conversion Engineering Conference. 1992, vol.3, pp. 3.489-3.492.

[9]R. K. Chen, JOM, 2013, 65, 702-708.

[10]M. Ioannou, G. Polymeris, E. Hatzikraniotis, A. U. Khan, K. M. Paraskevopoulos and T. Kyratsi, J. Electron. Mater., 2013, 42, 1827-1834.

[11]C. M. Xiao, N. Du, H. Zhang and D. R. Yang, J. Alloy. Compd., 2014, 587, 807-811.

[12]A. Kohandehghan, P. Kalisvaart, M. Kupsta, B. Zahiri, B. S. Amirkhiz, Z. P. Li, E. L. Memarzadeh,

L. A. Bendersky and D. Mitlin, J. Mater. Chem. A, 2013, 1, 1600-1612.

[13]T. Kato, Y. Sago and H. Fujiwara, J. Appl. Phys., 2011, 110, 063723.

[14]L. Wang, X.Qin, W. Xiong, and X. Zhu, Mater. Sci. Eng. A, 2007,459, 216-222.

[15]J. I.Tani, M. Takahashi and H. Kido, J. Alloy. Compd., 2009, 488, 346-349.

[16]J.I. Tani and H. Kido, Intermetallics, 2008, 16, 418-423.

[17]X. Zhang, Q. M. Lu, L. Wang, F. P. Zhang and J. X. Zhang, J. Electron. Mater, 2010, 39, 1413-1417.

[18]S. K. Bux, M. T. Yeung, E. S. Toberer, G. J. Snyder, R. B. Kaner and J. P. Fleurial, J. Mater. Chem., 2011, 21, 12259-12266.

[19]M. Akasaka, T. Iida, A. Matsumoto, K. Yamanaka, Y. Takanashi, T. Imai and N. Hamada, J. Appl. Phys., 2008, 104.

[20]E. Savary, F. Gascoin and S. Marinel, Dalton Trans., 2010, 39, 11074-11080.

[21]D. Horvitz and I. Gotman, Int. J. Self-Propag. High-Temp. Synth., 2003, 11(3), 289-297.

[22]H. J. Lee, Y. R. Cho and I. H. Kim, J. Ceramic Processing Research, 2011, 12, 16-20.

[23]W. Liu, Q. Zhang, K. Yin, H. Chi, X. Y. Zhou, X. F. Tang and C. Uher, J. Solid State Chem., 2013, 203, 333-339.

[24]X. Zhang, H. L. Liu, Q. M. Lu, J. X. Zhang and F. P. Zhang, Appl. Phys. Lett., 2013, 103(6), 3901.

[25]L. Wang, X Qin, Scripta materialia, 2003, 49, 243-248.

[26]H. Gao, T. Zhu, X. Liu, L. Chen and X. Zhao, J. Mater. Chem., 2011, 21(16), 5933-5937.

[27]T. Yi, S. Chen, S. Li, H. Yang, S. Bux, Z. X. Bian, N. A. Katcho, A. Shakouri, N. Mingo, J. P. Fleurial, N. D. Browning and S. M. Kauzlarich, J. Mater. Chem., 2012, 22(47), 24805-24813. 
[28]R. Marder, R. Chaim and C. Estournes, Mater. Sci. Eng. A, 2010, 527(6), 1577-1585.

[29]R. M. German, Sintering theory and practice, John Wiley\& Sons, Inc., Wiley, New York, 1996. [30]J.I. Tani and H. Kido, Physica B, 2005, 364, 218-224.

[31] M. J. Yang, W. J. Luo, Q. A. Shen, H. Y. Jiang and L. M. Zhang, in Advanced Synthesis and Processing Technology for Materials, eds. T. Goto, Y. B. Cheng, Z. G. Fu and L. M. Zhang, 2009, 66, 17-20. 


\section{Figure}

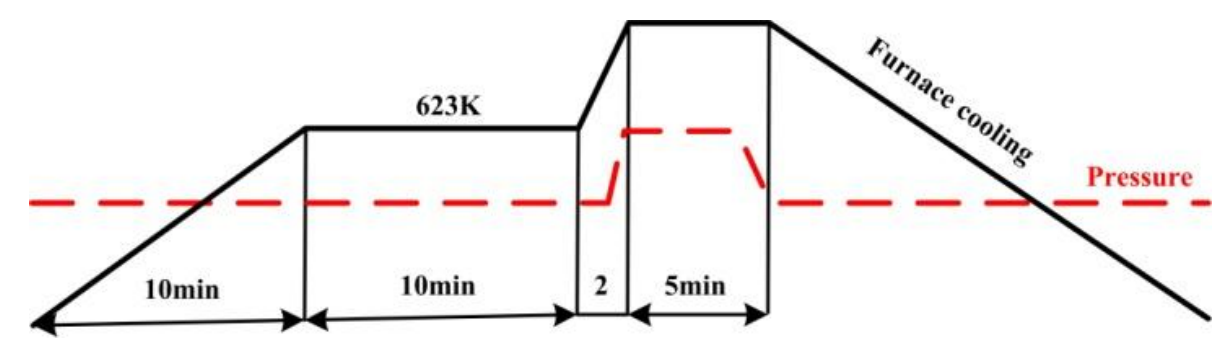

Fig.1 Schematic representation of the one-step reaction and consolidation process.

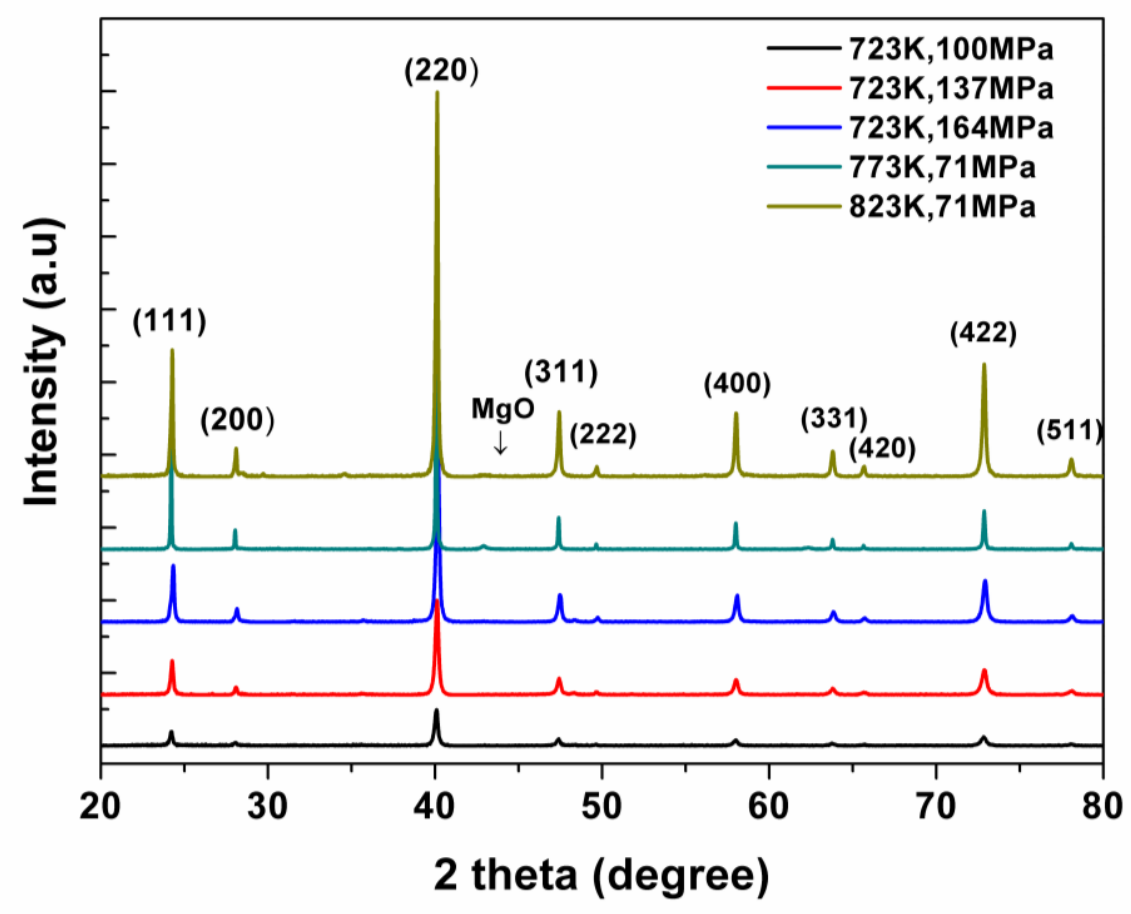

Fig.2 XRD patterns showing the effect of temperature and pressure. 

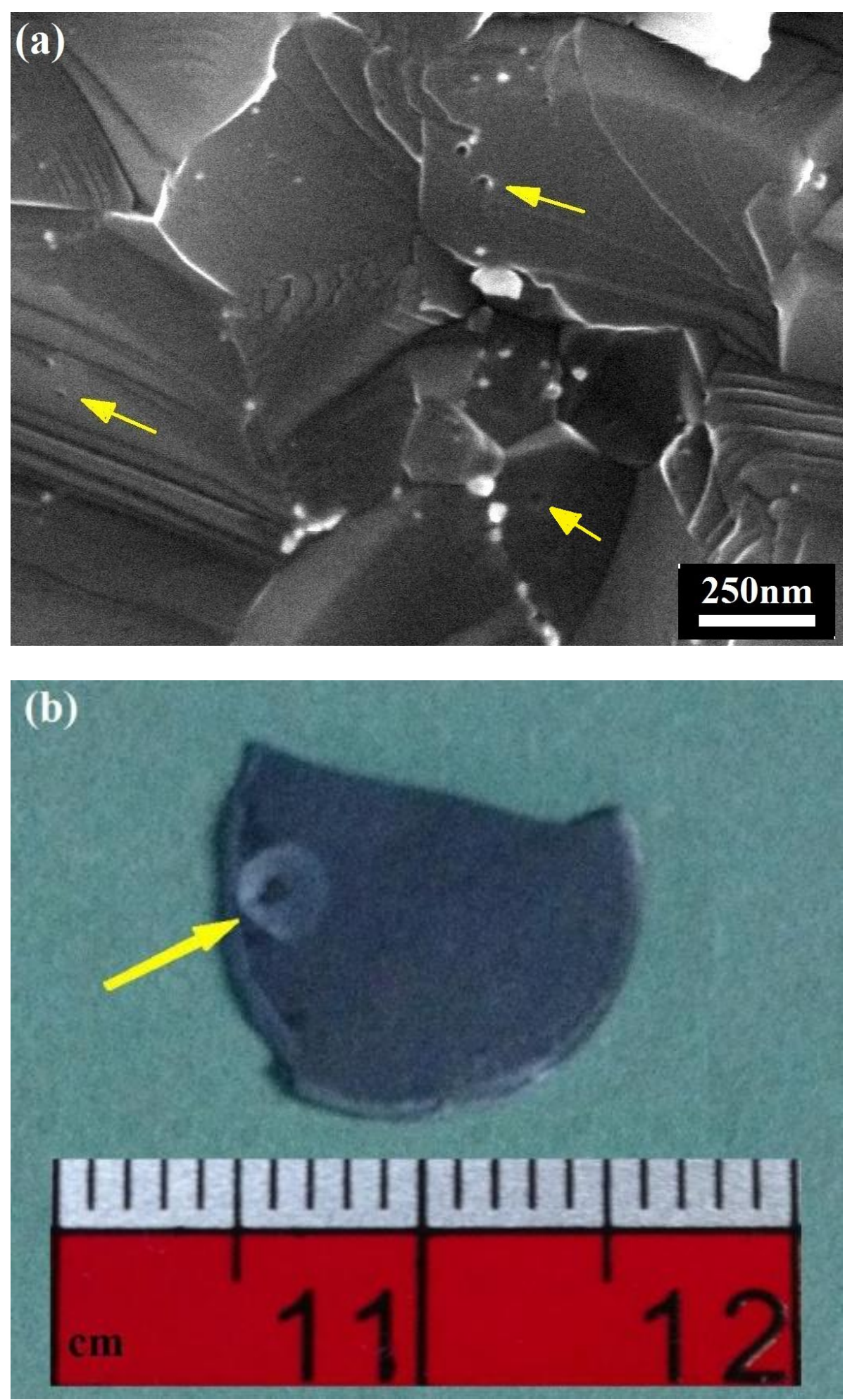

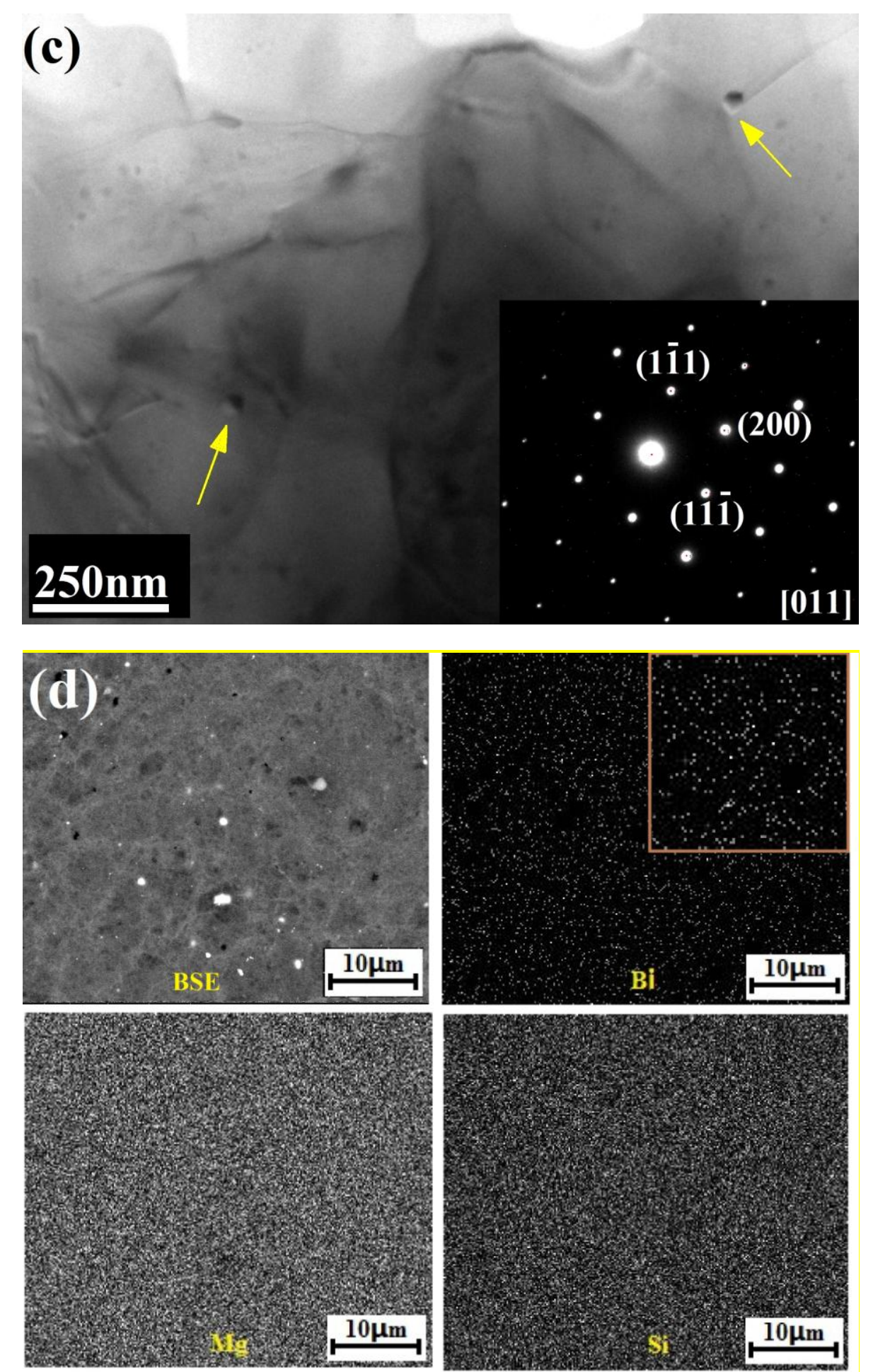

Fig. 3 (a) SEM image of sintered sample showing evidence of nano-pores. (b) Delayed pore formation on the surface of some samples. (c) TEM microstructure and SAD of 1 at.\% Bi doped $\mathrm{Mg}_{2} \mathrm{Si}$, (d) BSE image and EDS analysis of $1 \% \mathrm{Bi}$ doped $\mathrm{Mg}_{2} \mathrm{Si}$ consolidated at $823 \mathrm{~K}$. 

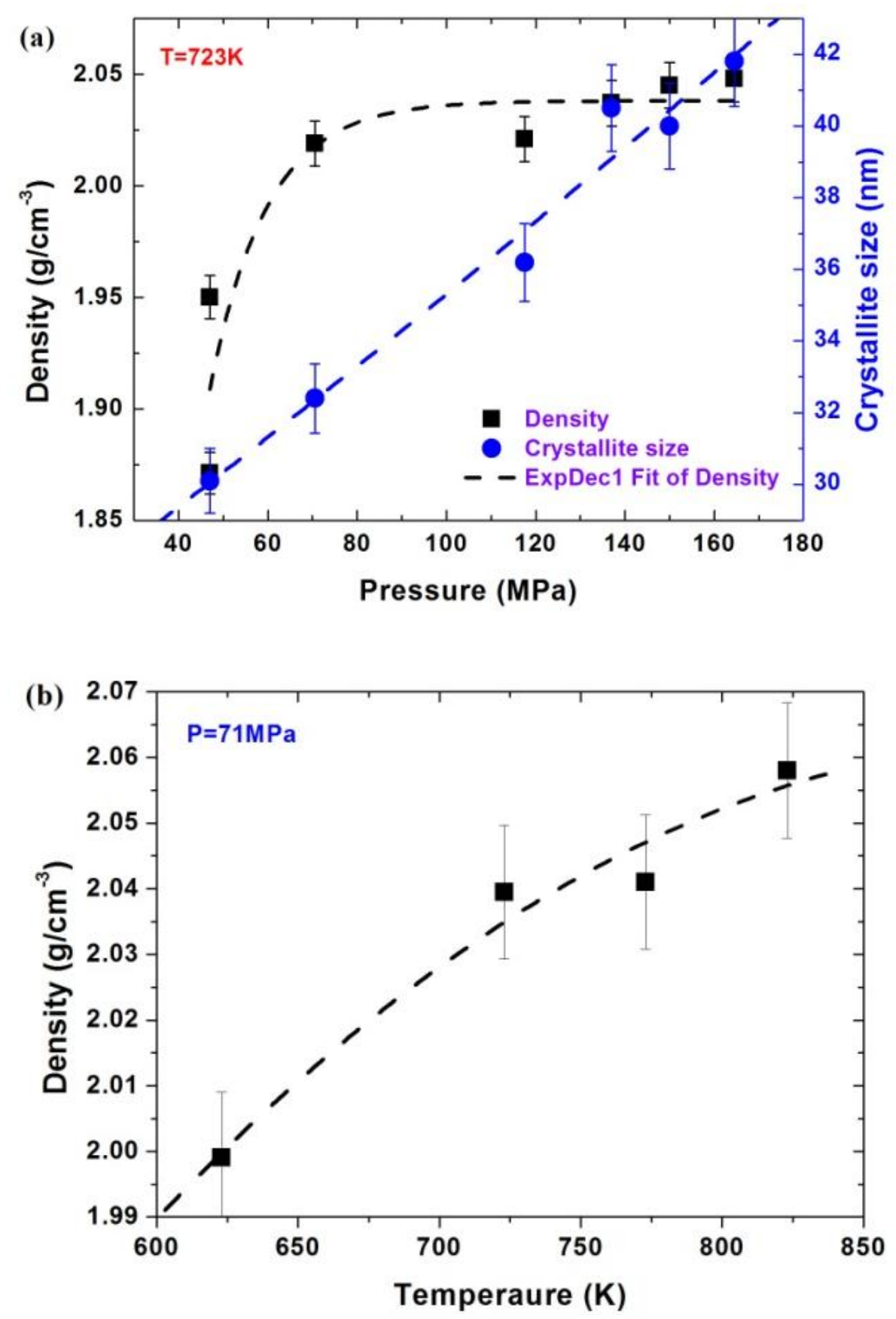

Fig. 4 (a) The effect of pressure on density and crystallite size; (b) The effect of temperature on density, of 1 at. $\%$ Bi doped $\mathrm{Mg}_{2} \mathrm{Si}$. 

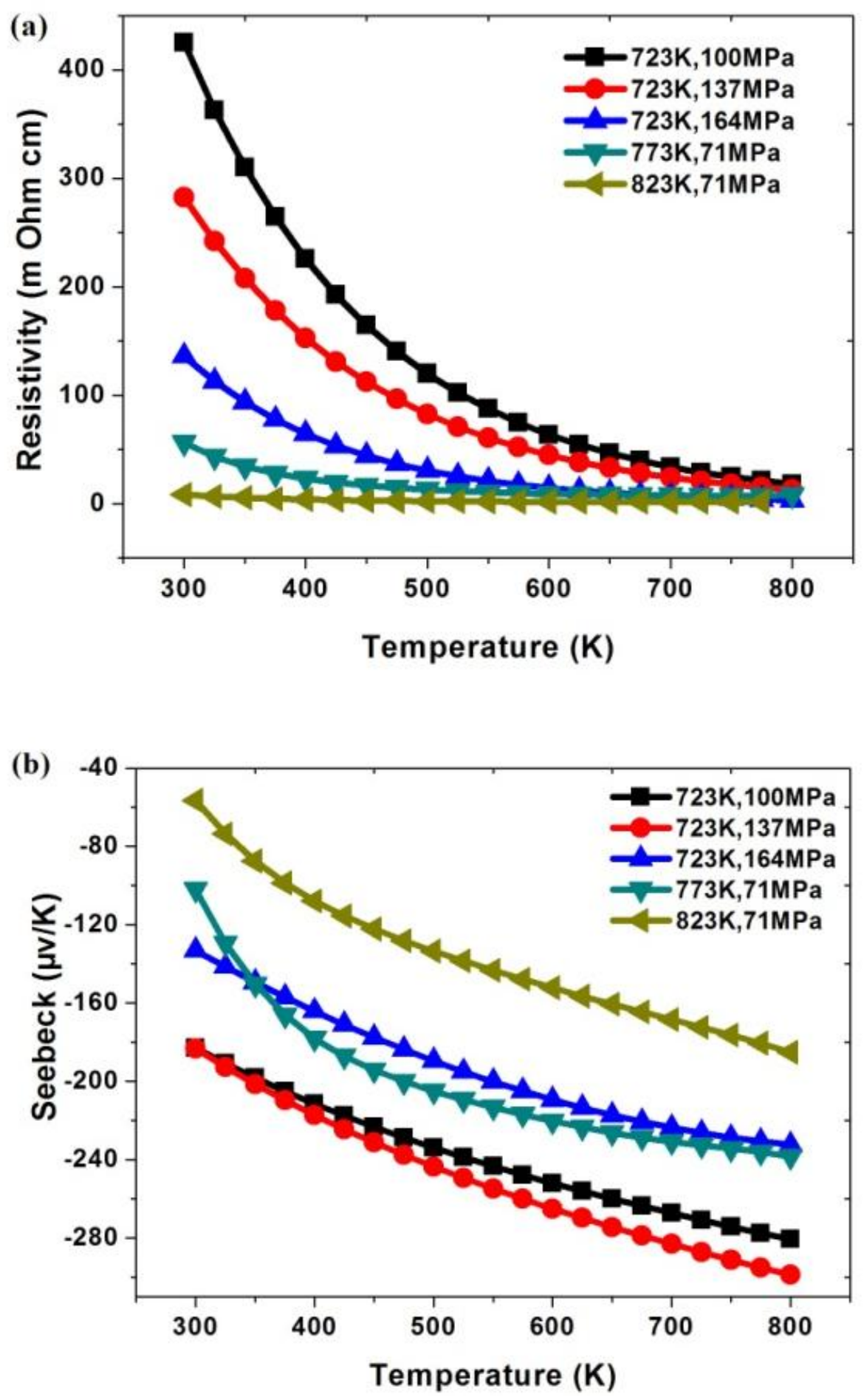


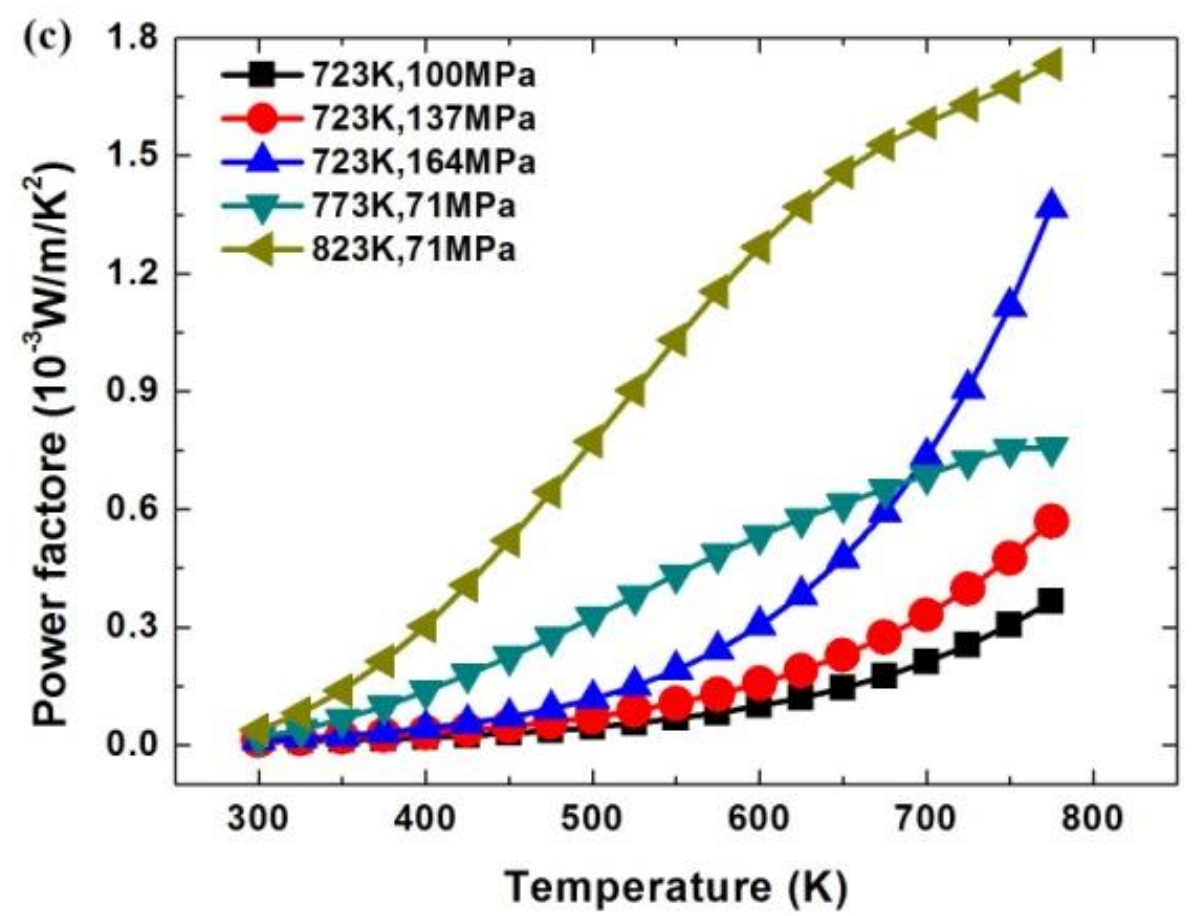

Fig. 5 Electrical resistivity (a), Seebeck coefficient (b) and Power factor (C) of 1 at.\% Bi doped $\mathrm{Mg}_{2} \mathrm{Si}$ prepared under different pressures and temperatures.

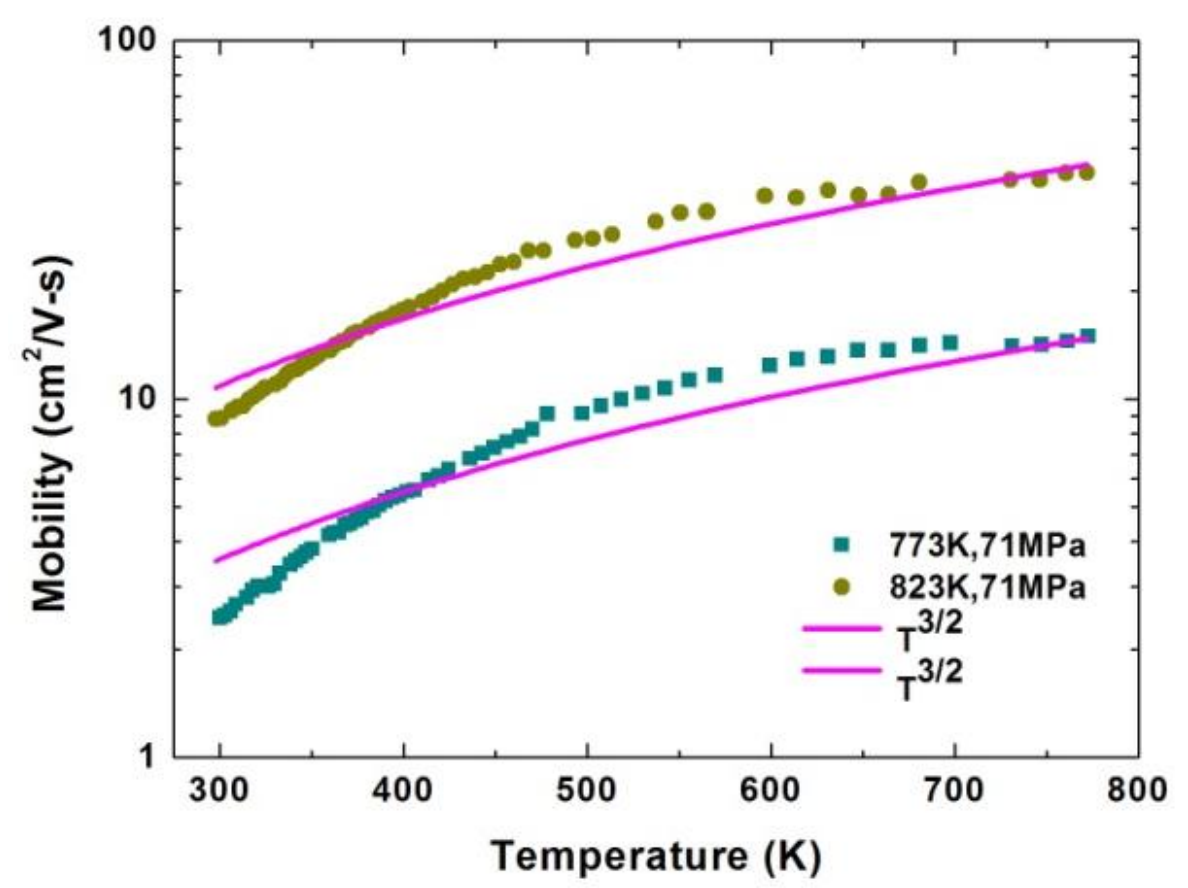

Fig. 6 Hall mobility change with temperature for 1 at.\% Bi doped $\mathrm{Mg}_{2} \mathrm{Si}$ as compared with $\mu \sim T^{3 / 2}$ dependence. 


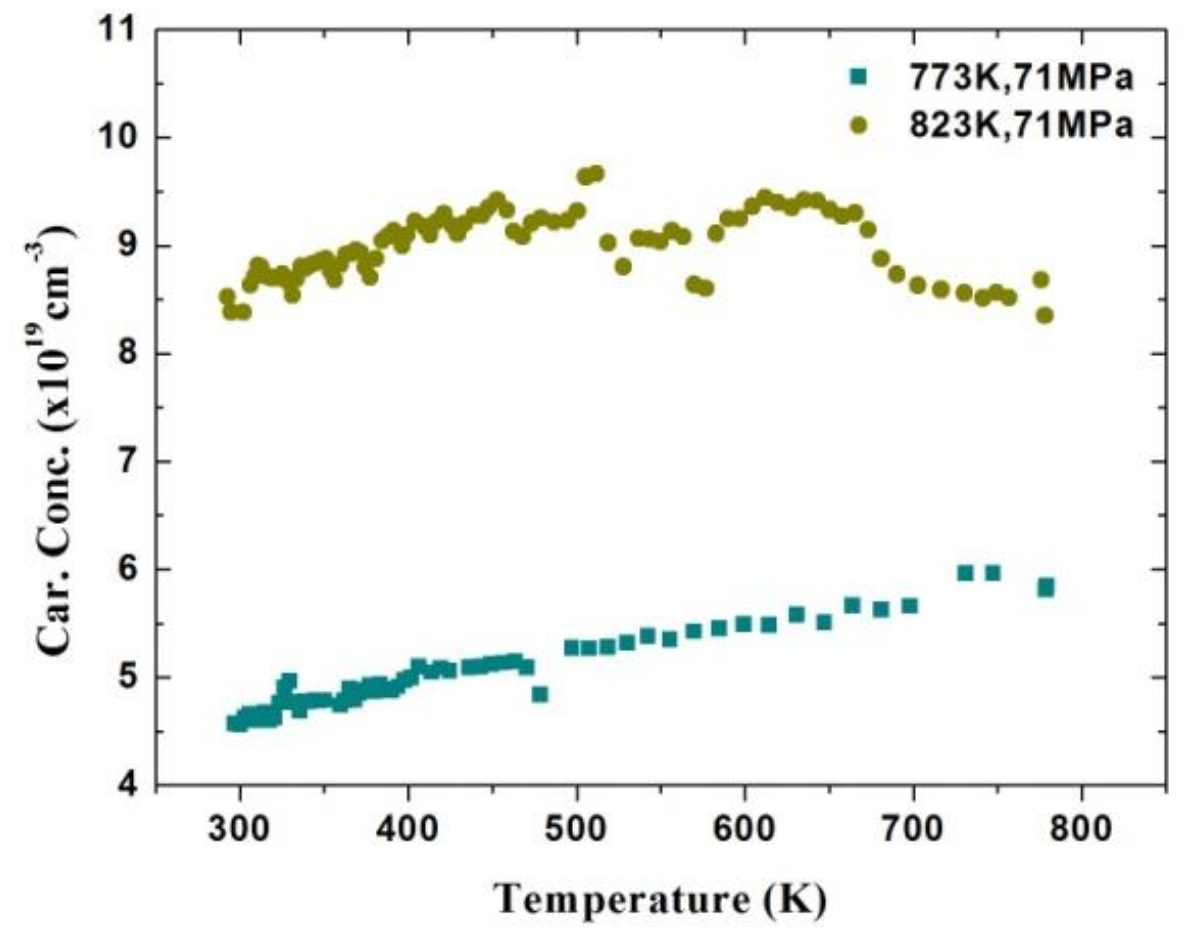

Fig. 7 The temperature dependence of the carrier concentration over the range of 300 $\mathrm{K}$ to $800 \mathrm{~K}$.

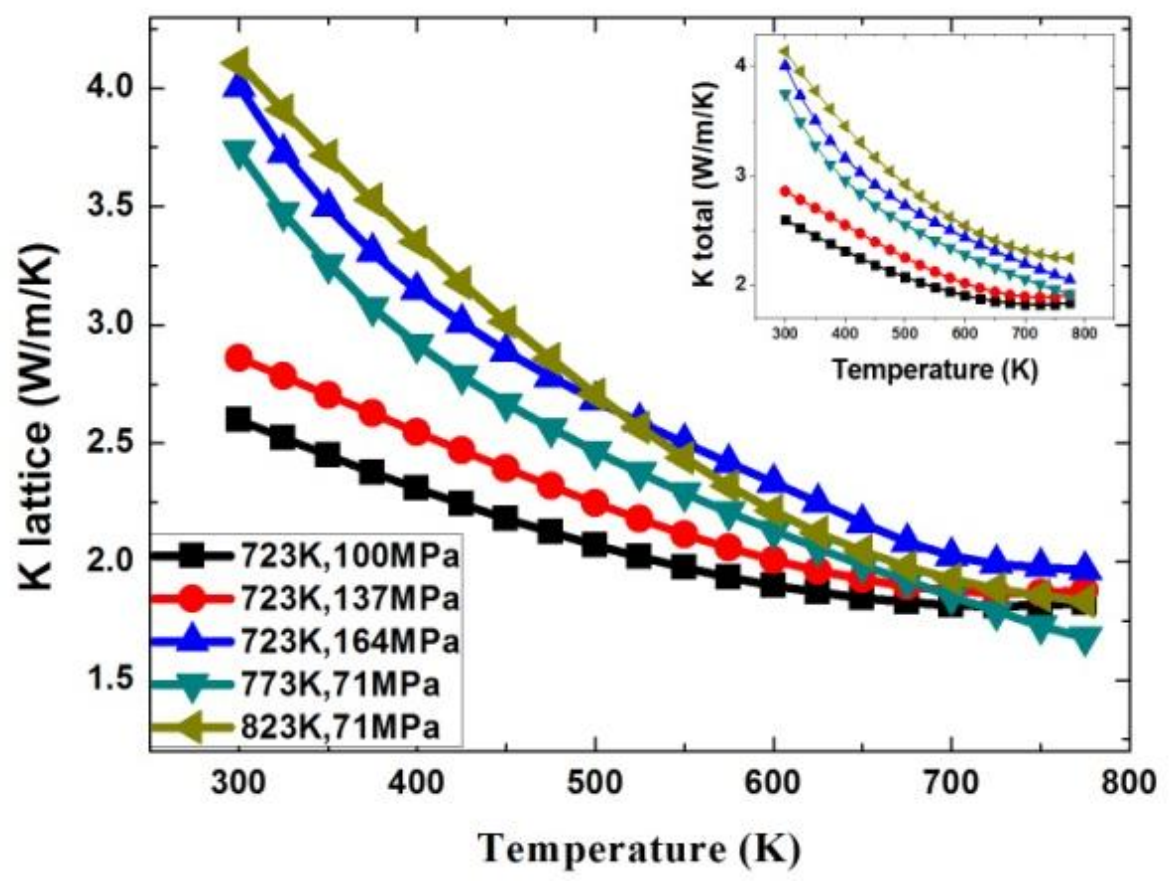

Fig. 8 Effect of temperature on the thermal conductivity of 1 at.\% Bi doped $\mathrm{Mg}_{2} \mathrm{Si}$ samples sintered at different temperatures and pressures. The total thermal conductivity is shown in inset. 


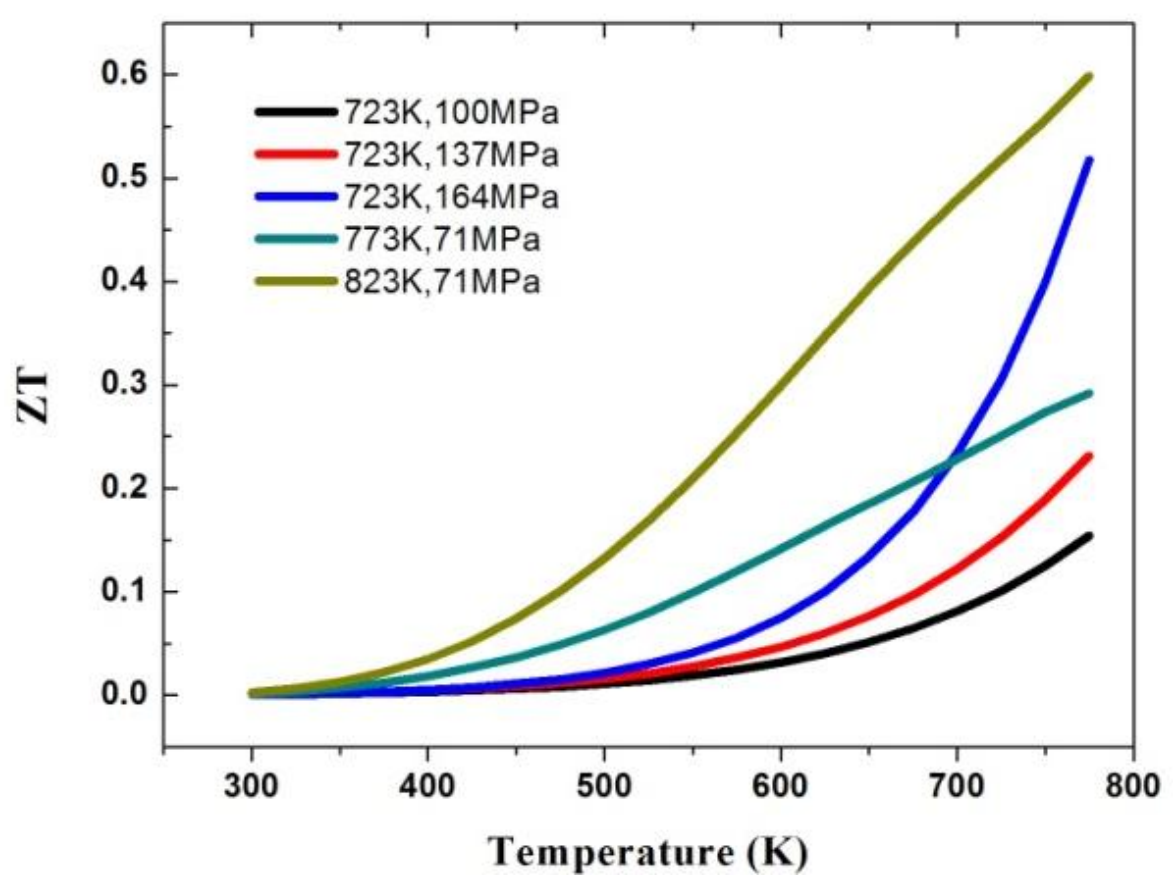

Fig. 9 Dependence of the figure of merit, $Z T$, of 1 at.\% Bi doped $\mathrm{Mg}_{2} \mathrm{Si}$ samples sintered at different temperatures and pressures. 